\title{
Versican and vascular endothelial growth factor expression levels in peritoneal metastases from colorectal cancer are associated with survival after cytoreductive surgery and hyperthermic intraperitoneal chemotherapy
}

\author{
N. R. Sluiter ${ }^{1}$ E. M. V. de $\mathrm{Cuba}^{1,2} \cdot$ R. Kwakman ${ }^{1}$ - W. J. H. J. Meijerink ${ }^{1}$ • \\ P. M. Delis-van Diemen ${ }^{2}$ V. M. H. Coupé ${ }^{3}$ J. A. M. Beliën ${ }^{2,4}$ - G. A. Meijer ${ }^{2,4}$. \\ I. H. J. T. de Hingh ${ }^{5}$ E. A. te Velde ${ }^{1}$
}

Received: 13 July 2015/Accepted: 1 February 2016/Published online: 12 February 2016

(C) The Author(s) 2016. This article is published with open access at Springerlink.com

\begin{abstract}
Cytoreductive surgery (CRS) and hyperthermic intraperitoneal chemotherapy (HIPEC) can increase survival of colorectal cancer (CRC) patients with peritoneal metastases (PM). This treatment is associated with high morbidity and mortality rates. Therefore, improvement of patient selection is necessary. Assuming that the clinical phenotype is dictated by biological mechanisms, biomarkers could play a crucial role in this process. Since it is unknown whether and to what extent angiogenesis influences the course of disease in patients with PM, we investigated the expression of two angiogenesis-related markers and their relation to overall survival (OS) in CRC patients after CRS and HIPEC. Clinicopathological data and tissue samples were collected from 65 CRC patients with isolated metastases to the peritoneum that underwent CRS and HIPEC. Whole tissue specimens from PM were
\end{abstract}

Electronic supplementary material The online version of this article (doi:10.1007/s10585-016-9779-9) contains supplementary material, which is available to authorized users.

E. A. te Velde

e.tevelde@vumc.nl

1 Section of Surgical Oncology and Digestive Surgery, Department of General Surgery, VU University Medical Centre, De Boelelaan 1117, 1081 HV Amsterdam, The Netherlands

2 Department of Pathology, VU University Medical Centre, De Boelelaan 1117, $1081 \mathrm{HV}$ Amsterdam, The Netherlands

3 Department of Epidemiology and Biostatistics, VU University Medical Centre, De Boelelaan 1117, 1081 HV Amsterdam, The Netherlands

4 Department of Pathology, NKI-Antoni van Leeuwenhoek, Plesmanlaan 121, 1066 CX Amsterdam, The Netherlands

5 Department of Surgery, Catharina Hospital Eindhoven, Michelangelolaan 2, 5623 EJ Eindhoven, The Netherlands evaluated for versican (VCAN) expression, VEGF expression and microvessel density (MVD) by immunohistochemistry. The relation between these markers and OS was assessed using univariate and multivariate analysis. Associations between VEGF expression, VCAN expression, MVD and clinicopathological data were tested. High stromal VCAN expression was associated with high MVD $(\mathrm{p}=0.001)$, better resection outcome $(\mathrm{p}=0.003)$ and high T-stage $(\mathrm{p}=0.027)$. High epithelial VCAN expression was associated with MVD $(\mathrm{p}=0.007)$ and a more complete resection $(\mathrm{p}<0.001)$. In multivariate analysis, simplified peritoneal cancer index $(\mathrm{p}=0.001)$, VEGF expression levels $(\mathrm{p}=0.012)$, age $(\mathrm{p}=0.030)$, epithelial VCAN expression levels $(\mathrm{p}=0.042)$ and lymph node status $(\mathrm{p}=0.053)$ were associated with OS. Concluding, VCAN and VEGF were associated with survival in CRC patients with PM after CRS and HIPEC. Independent validation in a well-defined patient cohort is required to confirm the putative prognostic role of these candidate biomarkers.

Keywords Peritoneal metastases - Colorectal cancer . HIPEC · Versican · VEGF · Angiogenesis · Biomarkers

$\begin{array}{ll}\text { Abbreviations } \\ \text { CRC } & \text { Colorectal carcinoma } \\ \text { PM } & \text { Peritoneal metastases } \\ \text { CRS } & \text { Cytoreductive surgery } \\ \text { HIPEC } & \text { Hyperthermic intraperitoneal chemotherapy } \\ \text { VCAN } & \text { Versican } \\ \text { VEGF } & \text { Vascular endothelial growth factor } \\ \text { MVD } & \text { Microvessel density } \\ \text { ECM } & \text { Extracellular matrix } \\ \text { MMC } & \text { Mitomycin C } \\ \text { PCI } & \text { Peritoneal cancer index }\end{array}$




\section{Introduction}

Cytoreductive surgery (CRS) combined with hyperthermic intraperitoneal chemotherapy (HIPEC) is the preferred therapeutic strategy for patients with isolated peritoneal metastases (PM) originating from colorectal cancer (CRC) $[1,2]$. This approach results in a median survival ranging from 33 to 45 months [3-7]. A recent meta-analysis even suggests that the combination of CRS and HIPEC compared to treatment with modern systemic chemotherapy potentially improves outcome in a carefully selected group of patients with both PM and liver metastases [8].

Treatment with CRS and HIPEC has considerable morbidity and mortality rates of $15-34$ and $5 \%$ respectively $[3,6,9,10]$, with anastomotic leakage being the most common cause of mortality. Consequently, a relatively long median hospital stay of 16 days is observed [5]. The high morbidity and mortality rates significantly impact the quality of life [7] and thus selection of patients that will benefit most from this treatment is key. Prediction of patient response to the surgical procedure and chemotherapeutic compounds will help bring the proper treatment to the right patient, providing a much needed step forward towards personalised medicine [11]. Assuming that the clinical phenotype of this disease is ultimately dictated by biological mechanisms, read-outs of these mechanisms (i.e., biomarkers) might aid in predicting treatment outcomes [12].

More specifically, identifying biomarkers requires knowledge of molecules that contribute to peritoneal dissemination. Peritoneal dissemination is viewed as a multistep process, in which the establishment of a metastatic lesion ultimately depends on colonisation of cancer cells and the creation of a metastatic niche [11]. At this step, the formation of a tumour-specific microenvironment is pivotal. Interactions between cancer cells and their surrounding stroma provide growth and survival signals necessary to evade apoptosis, to enable invasion and migration, and to provide oxygen and nutrients through angiogenesis [1316]. Angiogenesis is crucial for tumour growth beyond $150-200 \mu \mathrm{m}$ from the nearest blood vessel and for progression of micrometastases to macrometastases [14, 17, 18]. Consequently, angiogenesis influences tumour progression and is associated with higher morbidity and mortality rates in HIPEC patients, as is suggested by several authors [19,20]. Angiogenesis depends on complex interactions between several cell types and extracellular matrix (ECM) components [17]. The exact interactions required for this process are not fully understood. In an other study we did not find correlations between the angiogenesis related markers hypoxia-inducible factor $1 \alpha$ (HIF1 $\alpha$ ), stromal derived factor 1 (SDF1), CXC chemokine receptor 4 (CXCR4) and vascular endothelial growth factor (VEGF) [19]. Several other studies, however, suggest a role for versican (VCAN) [21-24]. VCAN is a sulphate proteoglycan overexpressed in a variety of human malignant tumours, including CRC [21, 25-31]. VCAN-mediated angiogenesis possibly depends upon interaction with VEGF. VEGF-A induced microvessel formation was accompanied by VCAN degradation and subsequent resynthesis [32]. In human astrocytoma cells VCAN was shown to form a complex with fibronectin and VEGF. This complex enhanced endothelial cell adhesion, proliferation and migration, possibly providing the molecular basis by which VCAN promotes angiogenesis [33]. It is not known, however, whether and to what extent VCAN influences the course of disease in PM patients. Additionally, the relation between VCAN expression, VEGF expression and angiogenesis has not yet been investigated in PM. The aim of the present study is to assess the possible role of VCAN as a prognostic biomarker in CRC patients with PM who underwent treatment with CRS and HIPEC. Secondly, correlations between VCAN and VEGF expression levels, microvessel density (MVD) and clinicopathological parameters were evaluated.

\section{Methods}

\section{Treatment: CRS and HIPEC}

In two tertiary referral centres, the Catharina Hospital Eindhoven from 2007 to 2010 and the VU University Medical Centre Amsterdam from 2010 to June 2013, 78 patients with PM of CRC were treated with CRS and HIPEC with curative intent. Both institutions performed the CRS and HIPEC procedure by following the same standardised protocol [5]. Complete debulking, stripping of the affected parietal peritoneum, and removal of the omentum and adnexa was performed as described by Sugarbaker et al. [1]. When deemed necessary, multi-organ resections were carried out. Subsequently, intra-abdominal lavage with Mitomycin C (MMC), $35 \mathrm{mg} / \mathrm{m}^{2}$ body surface, was performed with a target intraperitoneal temperature of $39-41{ }^{\circ} \mathrm{C}$ for $90 \mathrm{~min}$.

\section{Patient selection and data collection}

Patients with PM of non-colorectal origin $(n=2)$ were excluded. Specimens of 11 patients were not eligible for analysis due to loss of tissue or technical difficulties, leaving 65 patients eligible for further analysis.

Clinicopathological characteristics and follow-up data were collected from patient records of both institutions 
(Table 1). Resection outcome was determined according to the maximal size of residual tumour tissue. An R1 resection was recorded when no macroscopically visible tumour was left behind, an $\mathrm{R} 2 \mathrm{a}$ resection when the residual macroscopic tumour was smaller than $2.5 \mathrm{~mm}$ and an R2b resection when macroscopically tumour deposits larger than $2.5 \mathrm{~mm}$ remained [34].

Tumour specimens were collected during CRS and preserved as formalin-fixed paraffin-embedded (FFPE) tissue. Collection, storage and use of clinicopathological data and tissue specimens were performed in compliance with the 'Code for Proper Secondary Use of Human Tissue' in The Netherlands.

\section{Assays and immunohistochemistry protocols}

Sections of histologically confirmed PM from CRC ( $4 \mu \mathrm{m})$ were mounted on glass slides and immunohistochemically stained for VCAN, VEGF and CD31. After deparaffinisation and rehydration, endogenous peroxidases were blocked with $0.3 \%$ hydrogen peroxide in methanol. Tissue sections were treated with $10 \mathrm{mM}$ citrate buffer $(\mathrm{pH}$ 6.0) in a microwave for $30 \mathrm{~min}$ at $90 \mathrm{Watts}$ for the VCAN staining and for $5 \mathrm{~min}$ at maximum power followed by $10 \mathrm{~min}$ at 360 Watts for the VEGF and CD31 staining. Sections were subsequently incubated overnight at 4 degrees Celsius with primary mouse anti-VCAN antibody (clone 2-B-1, Seikagaku, Tokyo, Japan; dilution 1:300) and anti-VEGF antibody labelling the VEGF-121, VEGF-165 and the VEGF189 isoforms (clone v91, Dako, Carpinteria, USA, dilution $1: 50)$ and incubated for $1 \mathrm{~h}$ at room temperature with antiCD31 antibody (clone JC70A, Dako, Carpinteria, USA, dilution 1:50). Signals were visualised with a horseradish peroxidase-coupled anti-mouse polymer (Envision, Dako, Heverlee, Belgium) for VCAN and a poly-HRP-GAM/R/R $\mathrm{IgG}$ (PowerVision) for VEGF and CD31. This procedure was followed by diaminobenzidine (Dako) and Mayer's haematoxylin counterstain.

\section{Evaluation of protein expression}

Initially, tissue samples were scored for VCAN and VEGF intensity in four categories (negative, weak, moderate and strong, Fig. 1) but dichotomised into two categories: negative and weak as low expression versus moderate and strong as high expression for VCAN and weak and moderate as low expression versus strong as high expression for VEGF. Cut-offs were determined that discriminated best between the low and high expressing groups using the Kaplan-Meier method. Scoring was done using a $\times 20$ magnification $(\times 20 / 0.45$, diameter $0.98 \mathrm{~mm})$, depending on lesion size. Staining pattern and the location of protein
Table 1 Clinicopathological characteristics of 65 colorectal cancer patients with peritoneal metastases

\begin{tabular}{|c|c|c|}
\hline Characteristic & $\mathrm{n} / \mathrm{mean} /$ median & $\% / \mathrm{SD} /$ range \\
\hline \multicolumn{3}{|l|}{ General characteristics } \\
\hline All & 65 & \\
\hline Mean OS (months, range) & 34.4 & $29.4-39.2$ \\
\hline \multicolumn{3}{|l|}{ Gender } \\
\hline Male $(\%)$ & 25 & 38.5 \\
\hline Female $(\%)$ & 40 & 61.5 \\
\hline \multicolumn{3}{|c|}{ Age at CRS and HIPEC (years) } \\
\hline Mean (SD) & 59.6 & 11.6 \\
\hline Median (range) & 62 & $31-78$ \\
\hline \multicolumn{3}{|c|}{ Follow-up after CRS and HIPEC (months) } \\
\hline Mean (SD) & 21.0 & 10.8 \\
\hline Median (range) & 21.0 & $2-50$ \\
\hline \multicolumn{3}{|l|}{ Primary tumour characteristics } \\
\hline \multicolumn{3}{|l|}{ Location primary tumour } \\
\hline Colon $(\%)$ & 49 & 75.4 \\
\hline Rectum $(\%)$ & 5 & 7.7 \\
\hline Rectosigmoid (\%) & 11 & 16.9 \\
\hline \multicolumn{3}{|l|}{ Tumour differentiation } \\
\hline Poor $(\%)$ & 11 & 17.0 \\
\hline Moderate $(\%)$ & 22 & 33.8 \\
\hline Well $(\%)$ & 3 & 4.6 \\
\hline Unknown $(\%)$ & 29 & 44.6 \\
\hline \multicolumn{3}{|l|}{ Tumour histology } \\
\hline Adenocarcinoma (\%) & 39 & 60.0 \\
\hline Mucinous (\%) & 22 & 33.8 \\
\hline Signet cell $(\%)$ & 4 & 6.2 \\
\hline \multicolumn{3}{|l|}{ Lymph node involvement } \\
\hline Yes $(\%)$ & 46 & 70.8 \\
\hline No $(\%)$ & 17 & 26.2 \\
\hline Unknown $(\%)$ & 2 & 3.1 \\
\hline \multicolumn{3}{|l|}{ T-stage primary tumour } \\
\hline $\mathrm{T} 1(\%)$ & 1 & 1.5 \\
\hline $\mathrm{T} 2(\%)$ & 2 & 3.1 \\
\hline $\mathrm{T} 3(\%)$ & 27 & 41.5 \\
\hline $\mathrm{T} 4(\%)$ & 34 & 52.3 \\
\hline Unknown $(\%)$ & 1 & 1.5 \\
\hline \multicolumn{3}{|l|}{ Stage primary tumour } \\
\hline Stage $1(\%)$ & 1 & 1.5 \\
\hline Stage $2(\%)$ & 10 & 15.4 \\
\hline Stage $3(\%)$ & 18 & 27.7 \\
\hline Stage $4(\%)$ & 35 & 53.8 \\
\hline Unknown $(\%)$ & 1 & 1.5 \\
\hline \multicolumn{3}{|l|}{ PM characteristics } \\
\hline \multicolumn{3}{|l|}{ Synchronous PM } \\
\hline Yes $(\%)$ & 35 & 53.8 \\
\hline No $(\%)$ & 30 & 46.2 \\
\hline Simplified PCI & & \\
\hline
\end{tabular}


Table 1 continued

\begin{tabular}{lll}
\hline Characteristic & n/mean/median & $\% / \mathrm{SD} /$ range \\
\hline$<2(\%)$ & 1 & 1.5 \\
$2-4(\%)$ & 42 & 64.6 \\
$5(\%)$ & 14 & 21.5 \\
$>5(\%)$ & 8 & 12.3 \\
Resection outcome & & \\
R1 (\%) & 37 & 56.9 \\
R2a (\%) & 22 & 33.8 \\
R2b (\%) & 6 & 9.2 \\
Adjuvant chemotherapy & & \\
Yes (\%) & 41 & 63.1 \\
No (\%) & 24 & 36.9 \\
Pre-operative chemotherapy 6 months before HIPEC \\
Yes (\%) & 17 & 26.2 \\
No (\%) & 48 & 73.8
\end{tabular}

$O S$ overall survival, $C R S$ cytoreductive surgery, HIPEC hyperthermic intraperitoneal chemotherapy, $P M$ peritoneal metastases, simplified $P C I$ peritoneal cancer index

expression were assessed. VCAN staining was expressed in the cytoplasm of tumour cells and in the stroma surrounding the tumour cells. Hence, both stromal and epithelial VCAN were analysed. Since VEGF was predominantly seen in the cytoplasm of tumour cells, its intensity was scored in the cytoplasmic compartment. All tissue sections were scored and examined blinded to clinicopathological data. Fifteen per cent of sections were analysed independently in a blinded fashion by a second investigator (NRS and EMVdC) with high inter-observer agreement for all stainings (Cohen's weighted kappa value, VEGF $\mathrm{K}_{\mathrm{w}}=0.82$, epithelial $\mathrm{K}_{\mathrm{w}}=0.65$, stromal VCAN $\left.\mathrm{K}_{\mathrm{w}}=0.74\right)$

MVD was determined by automated image analysis of CD31 staining patterns. In short, complete slides were scanned with a digital Mirax slide Scanner system (3DHISTECH, Budapest, Hungary). The scan resolution of all pictures at $\times 20$ was $0.23 \mu \mathrm{m}$. Next, areas with tumour tissue were manually selected using the Panoramic Viewer software (3DHISTECH) and exported in the TIFF imageformat. A computerised morphometric analysis of the CD31 stained slides was executed using ImageJ. The CD31 staining was used to quantify the amount of microvessels per area as the percentage of the field of view that was CD31 positive [35]. Morphometric measurements were performed without knowledge of sample identity. For survival analysis, MVD was dichotomised as 'low' and 'high' if respectively less than $31.0 \%$-the mean MVD percentage- and more than $31.0 \%$ of the analysed area was stained positive for CD31.

\section{Statistical analysis}

Associations between the staining intensities of the markers and clinicopathological variables were studied by means of the Spearman's correlation coefficient (two continuous variables), the Fisher's Exact Test (two categorical/dichotomous variables) or the Kruskal-Wallis test (a continuous non-normally distributed variable with a categorical/dichotomous variable) [36]. Associations were considered statistically significant for $p$ values smaller than or equal to 0.05 (two sided test).

Overall survival (OS) was defined as time in months from date of surgery to death from any cause. Patients were censored at date last known to be alive. Univariate associations between OS and potential prognostic variables were studied by means of Kaplan-Meier analysis and tested using the log-rank test (Table 3). Variables with a $p$ value $\leq 0.1$ and possible relevant markers were included in a multivariate Cox regression analysis. Variable selection in the Cox model was done using backward selection with a threshold $\mathrm{p}$ value of 0.1 for exclusion from the model.

All data were reported according to the REMARK guidelines. Statistical analyses were performed using the package for the social sciences version 20 for OsX (IBM, Armonk, NY, USA).

\section{Results}

\section{Associations between VCAN, VEGF, MVD and clinicopathological characteristics}

Significant associations between markers and clinicopathological variables are listed in Table 2. A complete overview of all associations is shown in supplementary Table 1a-d. VCAN was expressed in both the epithelial and the stromal compartment. Stromal VCAN was negative in $1.5 \%$, weak in $28.4 \%$, moderate in $32.8 \%$ and strong in $37.3 \%$ of patients (Fig. 1a-c). The group patients with high stromal VCAN expression had an MVD of $34.4 \%$ (SD 12.6) and the group with low stromal VCAN expression an MVD of $22.4 \%$ (SD 7.7) $(\mathrm{p}=0.001)$. Furthermore, we found high VCAN expression in the stromal compartment to be associated with better resection outcome $(\mathrm{p}=0.003$, odds ratio $[\mathrm{OR}] 0.17,95 \%$ CI 0.053-0.53, Table 2) and higher T-stage of the primary tumour ( $\mathrm{p}=0.027$, OR 3.59, $95 \%$ CI 2.40-5.37, Table 2).

Epithelial VCAN was negative in $13.4 \%$, weak in $14.9 \%$, moderate in $26.9 \%$ and strong in $44.8 \%$ (Fig. 1a-c). In the VCAN positive cells a cytoplasmic staining was seen, sometimes with a highly intense granular pattern, probably depicting the Golgi system [37]. In the patients with high 


\section{VCAN expression}

a

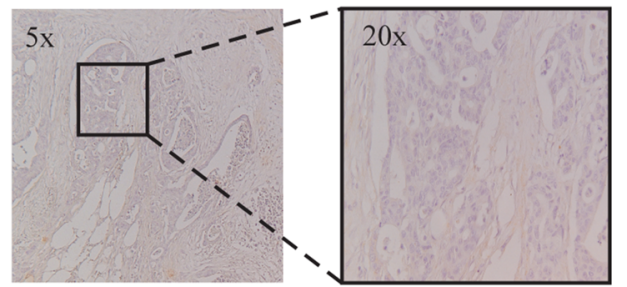

epithelial: negative (13.4\%)

stromal: weak $(28.4 \%)$

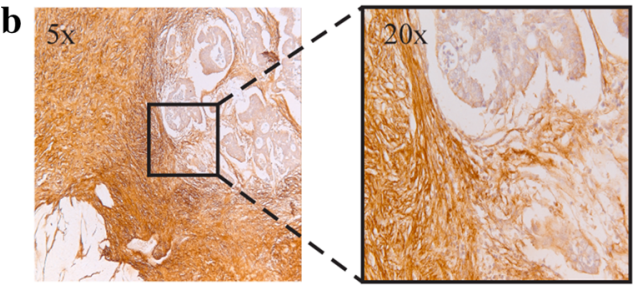

epithelial: moderate $(26.9 \%)$

stromal: strong $(37.3 \%)$

c

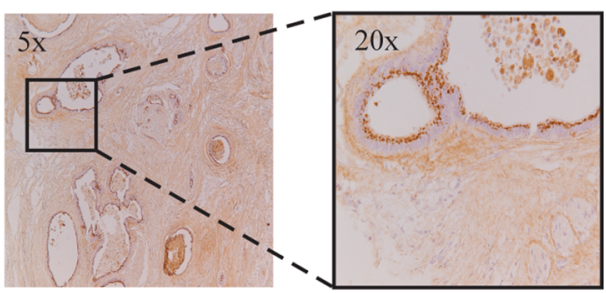

epithelial: strong (44.8\%), granular pattern stromal: moderate $(32.8 \%)$
VEGF expression

d

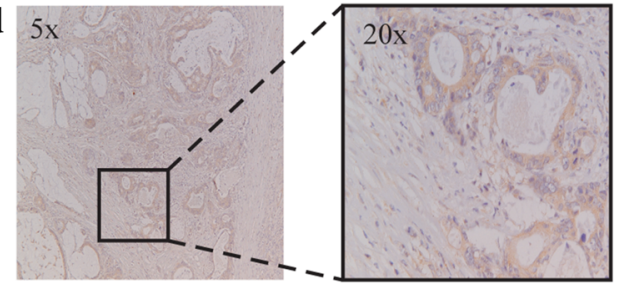

epithelial: weak (11.9\%)

e

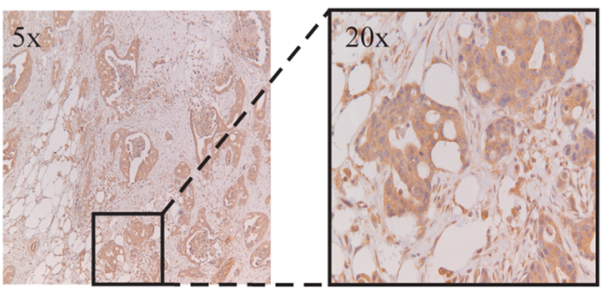

epithelial: moderate (43.4\%)

\section{f}

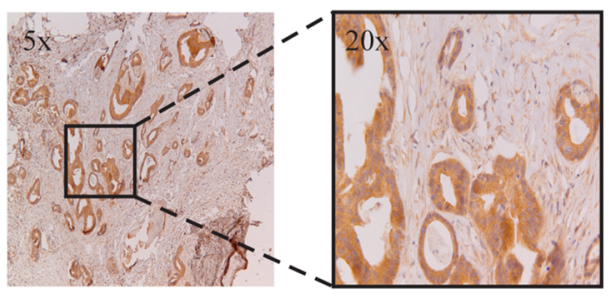

epithelial: strong (44.8\%)
MVD

$\mathbf{g}$

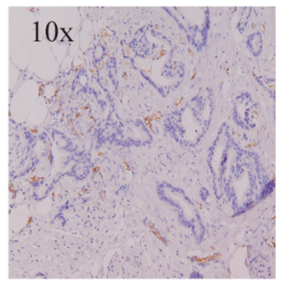

$16.6 \%$

$\mathbf{h}$

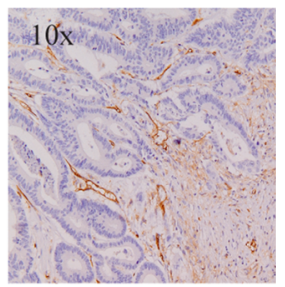

$23.0 \%$

i

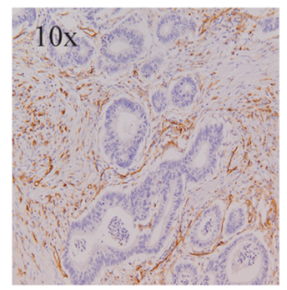

$35.4 \%$
Fig. 1 Representative examples of versican (VCAN) (a, b, c) and vascular endothelial growth factor (VEGF) (d, e, f) expression patterns and microvessel density (MVD) $(\mathbf{g}, \mathbf{h}, \mathbf{i})$ in peritoneal lesions. The magnification is shown on the micrographs. Intensities were classified as negative, weak, moderate or strong. Scoring percentages

epithelial VCAN expression an MVD of $33.9 \%$ (SD 12.4) was seen and in the patients with low epithelial VCAN expression an MVD of $22.9 \%$ (SD 9.6) $(\mathrm{p}=0.007)$. Both epithelial VCAN ( $\mathrm{p}<0.001$, OR 0.11, $95 \%$ CI 0.029-0.38, Table 2) and a granular epithelial VCAN expression pattern $(\mathrm{p}=0.001$, Table 2$)$ correlated with a more favourable resection outcome. In male patients, epithelial VCAN expression was mostly granular ( $\mathrm{p}=0.028$, Table 2$)$, which may be related to an androgen-mediated regulation of the VCAN gene [38].

VEGF expression in the cytoplasmic compartment of the tumour cells was detected in $100 \%$ of the patients. In $11.9 \%$ of these patients, weak VEGF expression, in $43.3 \%$ moderate VEGF expression and in $44.8 \%$ strong VEGF expression (Fig. 1d-e) was observed. No association was observed between epithelial VEGF expression and MVD $(\mathrm{p}=0.596)$, epithelial VCAN expression $(\mathrm{p}=$ $0.791)$ or stromal VCAN expression $(\mathrm{p}=0.595)$. of all markers are listed next. Stromal VCAN expression: negative $(1.5 \%)$, weak $(28.4 \%)$, moderate $(32.8 \%)$ and strong $(37.3 \%)$. Epithelial VCAN expression: negative (13.4\%), weak (14.9\%), moderate $(26.9 \%)$ and strong $(44.8 \%)$. VEGF expression: weak $(11.9 \%)$, moderate $(43.3 \%)$ and strong $(44.8 \%)$

The mean and median MVD were $31.0 \%$ (SD $12.4 \%$ ) and $28.9 \%$ (range $7.5-61.0 \%$ ) respectively. MVD correlated to stromal and epithelial VCAN, but did not show associations with other markers or clinicopathological characteristics.

\section{VEGF and epithelial VCAN are associated with OS in CRC patients with PM}

Mean OS in the patient cohort was 34.4 months (95\% CI 29.4-39.2, Table 1). Mean survival in the group patients with low VEGF expression was 38.3 months and in the group patients with high VEGF expression 29.2 months $(p=0.035)$. Mean survival in patients with high epithelial VCAN expression was 36.8 months and in patients with low epithelial VCAN expression 20.1 months $(\mathrm{p}=0.109)$. Furthermore, in patients with low and high stromal VCAN expression a mean survival of 34.9 and 33.8 months was 
Table 2 Significant associations between VCAN, VEGF, MVD and clinicopathological variables

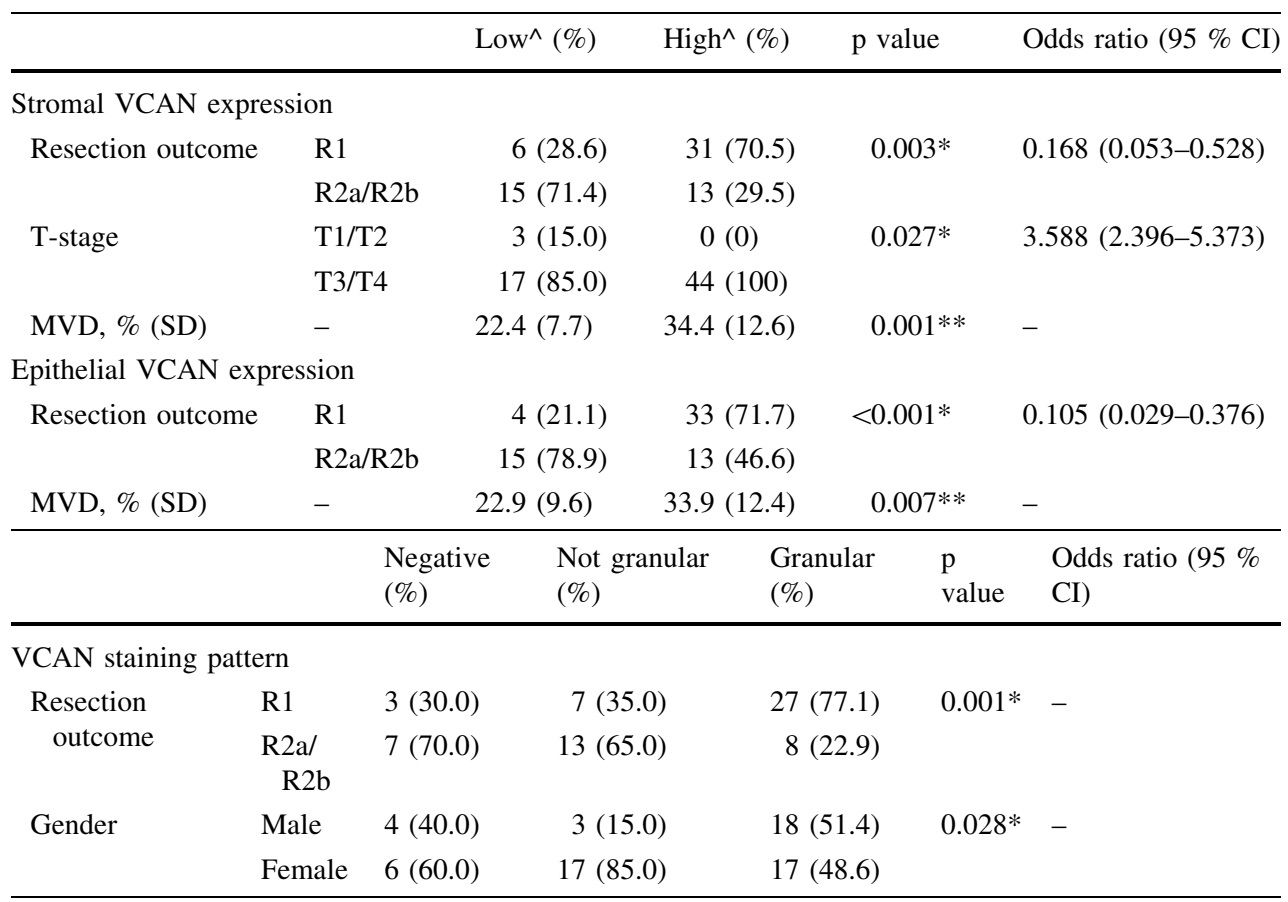

* Fisher's exact test; ** Kruskal-Wallis test

${ }^{\wedge}$ Low negative and weak expression, high moderate and weak expression observed respectively ( $p=0.996$, Fig. $2 d$ ). Mean survival in patients with low MVD was 36.5 months and in patients with high MVD mean survival was 29.0 months ( $\mathrm{p}=0.747$, Fig. 2b).

Possibly important characteristics included in the multivariate analysis after being individually tested for correlation with OS were age $(\mathrm{p}=0.056)$, lymph node status $(\mathrm{p}=0.042)$, simplified peritoneal cancer index (PCI) [39] $(\mathrm{p}=0.052)$, resection outcome $(\mathrm{p}=0.021)$, preoperative chemotherapy 6 months before HIPEC $(\mathrm{p}=0.007)$, VEGF $(\mathrm{p}=0.035)$ and epithelial VCAN $(\mathrm{p}=0.109)$ (Table 3$)$.

Variables that emerged as independent prognostic factors in the final model are listed in Table 3. In this model, high VEGF expression was significantly associated with worsened OS ( $\mathrm{p}=0.012$, Table 3; Fig. 2a). In contrast, high epithelial VCAN expression was significantly associated with longer OS $(0=0.042$, Table 3 ; Fig. 2 c). The observation of epithelial VCAN expression being significant in multivariate, but not in univariate analysis, is most probably attributable to the effect of confounding in the univariate analysis. This confounding effect is corrected for in multivariate analysis by including all possibly significant variables.

\section{Discussion}

Although CRS and HIPEC increase survival rates of CRC patients with isolated PM [5-8], this treatment has considerable morbidity and mortality rates $[3,6,9,10]$.
Selection of patients that will benefit most from this treatment is key. Biomarkers could help in patient selection, preventing unnecessary morbidity in patients that will not benefit. Because it is not known whether and to what extent angiogenesis influences the course of disease in PM patients, the present study evaluated the expression of potential markers of angiogenesis-VCAN, VEGF and MVD-in these patients. In the multivariate analysis, VEGF and epithelial VCAN expression levels were found to be significantly associated with OS in CRC patients with PM after CRS and HIPEC $(p=0.012$ and $p=0.042$ respectively, Table 3; Fig. 2a, c). Furthermore, both high stromal and epithelial VCAN were related to increased microvessel density (MVD) $(\mathrm{p}=0.001$ and $\mathrm{p}=0.007$ respectively).

The currently observed association between VEGF and OS in CRC patients with PM is in accordance with several other clinical and preclinical studies demonstrating VEGF to have a role in PM formation and prognosis [20, 40-50]. The possible role of VEGF as a predictor of worse outcome corroborates the rationale for (neo-) adjuvant anti-VEGF based therapy in selected patients [20, 51, 52]. Neo-adjuvant administration of this drug was shown to improve outcome in patients after CRS and HIPEC [53]. Although a recent study described a twofold increase in morbidity in these patients after administration of bevacizumab [54], a meta-analysis including more than 3000 patients with metastasised CRC reported the amount and severity of treatment with bevacizumab to be acceptable [3]. 

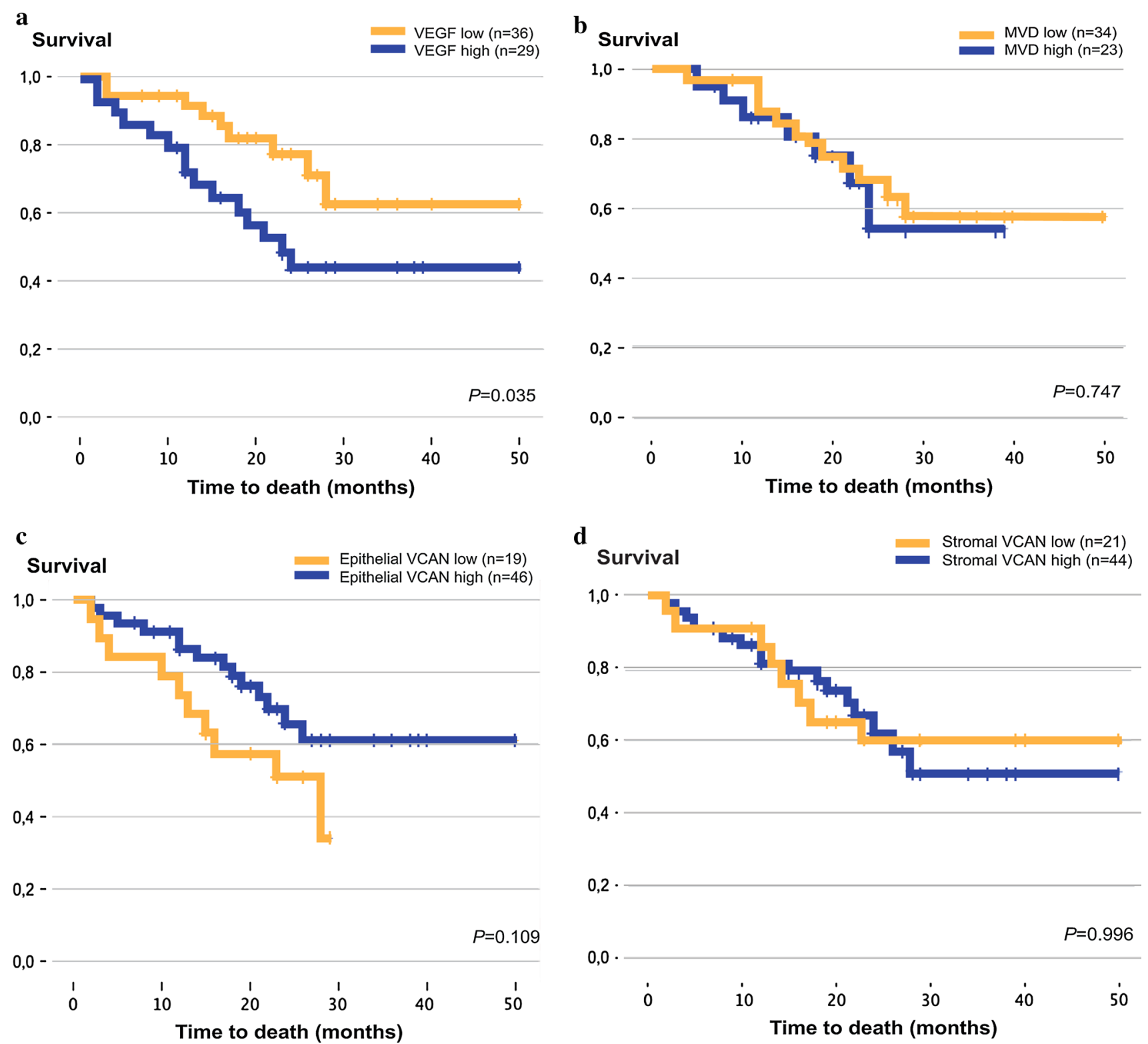

$0,2 \cdot$

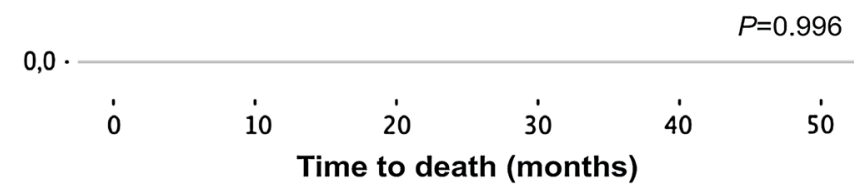

Fig. 2 Kaplan-Meier curves of all patients. The graphs depict the curves according to the dichotomised vascular endothelial growth factor (VEGF) (a), microvessel density (MVD) (b), epithelial versican (VCAN) (c) and stromal VCAN (d) categories

The sulphate proteoglycan VCAN is thought to promote tumour development $[21,55]$ by mediating several processes such as proliferation [56-58], drug resistance [27, 56-62], cell adhesion [57-60], invasion [57, 58, 63] and angiogenesis [23, 24, 32, 33, 64, 65]. Angiogenesis in astrocytoma [33] and breast cancer [64] was suggested to result from interaction between VCAN and VEGF. In the present study, VEGF was not correlated to MVD, a finding supported by others [20]. Interestingly, stromal and epithelial VCAN levels did correlate with MVD. MVD is a measure of the number of vessels per high power field. Considering this number of vessels is not only determined by angiogenic factors, such as VEGF, but also by non- angiogenic factors such as oxygen and nutrient consumption rates, one might state that MVD does not necessarily adequately reflect the rate of angiogenesis [66]. Hence, it is possible that MVD is a marker of a more or less established vessel network, whilst VEGF is produced in the presence of hypoxic stimuli to stimulate angiogenesis [67]. Once vessels are established and an oxygen-rich environment is created, VEGF is no longer necessary for the formation of new vessels. In the presence of an established vessel network, other molecules, including VCAN, might be required for maintenance -and not creation- of a favourable microenvironment $[14,21]$. To confirm this hypothesis, further experiments should focus on the exact mechanisms 
Table 3 Final model resulting from multivariate survival analysis

\begin{tabular}{llll}
\hline Variable* & Hazard ratio & $95 \%$ CI & p value \\
\hline Simplified PCI & 0.235 & $0.097-0.570$ & 0.001 \\
VEGF expression & 0.315 & $0.128-0.773$ & 0.012 \\
Age & 1.048 & $1.004-1.094$ & 0.030 \\
VCAN expression & 2.584 & $1.034-6.452$ & 0.042 \\
Lymph node status & 0.296 & $0.086-1.014$ & 0.053
\end{tabular}

* Variables tested for individual associations with OS (log rank): gender $(p=0.292)$, age $(p=0.056)$, histology class $(p=0.123)$, differentiation grade $(\mathrm{p}=0.888)$, T-stage $(\mathrm{p}=0.581)$, lymph node status $(\mathrm{p}=0.042)$, stage $(\mathrm{p}=0.270)$, location primary tumour $(\mathrm{p}=0.807)$, synchronous metastases versus metachronous metastases $(p=0.132)$, PCI index $(p=0.052)$, resection outcome $(p=0.021)$, chemotherapy in the 6 month before CRS and HIPEC $(p=0.007)$, adjuvant chemotherapy $(p=0.724)$, MVD $(p=0.747)$, VEGF expression $(\mathrm{p}=0.035)$, stromal VCAN expression $(\mathrm{p}=0.996)$, epithelial VCAN expression $(\mathrm{p}=0.109)$, a granular VCAN staining pattern $(\mathrm{p}=0.779)$, simultaneous high VEGF and epithelial VCAN expression $(\mathrm{p}=0.129)$ and simultaneous high VEGF and stromal VCAN expression $(\mathrm{p}=0.158)$

by which VEGF and VCAN possibly promote tumour growth in PM of CRC.

The present study revealed that epithelial VCAN is indicative for good survival in CRC patients with PM in multivariate analysis ( $p=0.042$, Table 3 ). This finding is supported by studies in primary CRC [37] and serous ovarian cancer [68]. The mechanism by which epithelial VCAN positively influences patient outcome might be related to tumour cell responses to chemotherapy [68]. Another study found cells transfected with V1 VCAN to be selectively sensitised to several apoptotic stimuli, for example to the chemotherapeutics etoposide and cisplatin [61]. The influence of molecules such as VCAN in tumour response to chemotherapy stresses the importance of systematically analysing interactions between cancer cells and their environment in order to identify mechanisms contributing to drug sensitivity. In peritoneal cancer patients, sensitivity of tumour cells to heated MMC might -at least in part- account for good outcome in patients with high epithelial VCAN expression. A recent paper found low Bloom syndrome protein (BLM) expression to be associated with high MMC sensitivity in CRC cell lines. Low BLM expression was thereby related to improved survival in CRC patients with PM [69]. Since identification of sensitivity and resistance mechanisms could lead to mechanism-based therapies and further stratification of HIPEC patients, i.e. personalised medicine, further research is warranted in this particular field. Another interesting finding is that both epithelial and stromal VCAN expression and a granular expression pattern are associated with a better resection outcome. An explanation for this, albeit speculative, might be related to the role of VCAN in creation of a microenvironment for tumour cells [21, 23, 24, 55-60, 64, 65]. In this way, VCAN plays a role in determining the consistency and appearance of tumour spots on the peritoneal surface, thereby possibly contributing to the extent to which these spots can be detected and subsequently resected.

In the current study, several possible markers were investigated in a study cohort consisting of HIPEC patients, representing a well-defined group of cancer patients with metastases confined to the peritoneum. In these patients, we found in the multivariate analysis high epithelial VCAN and VEGF expression to be associated with improved and worsened outcome respectively. To our knowledge, this is the first study examining stromal and epithelial VCAN expression in PM. We presume that higher VCAN expression is associated with improved sensitivity to chemotherapy, but this hypothesis should be further studied in vitro and in vivo and in well-defined patient cohorts. Further studies focusing of VCAN and other potential biomarkers could help improve selection of patients with $\mathrm{PM}$, in this way minimising unnecessary exposure to the high morbidity and mortality rates associated with HIPEC treatment. A more comprehensive understanding of VCAN based mechanisms contributing to peritoneal dissemination and patient responses to therapy will potentially result in a more personalised approach in CRC patients with PM, ultimately leading to better treatment outcomes.

Acknowledgments The authors would like to thank S. H. den Uil and E. van den Broek for their technical assistance.

\section{Compliance with ethical standards}

Conflicts of interest The VEGF antibody was made available in part by a grant from Roche Pharmaceuticals.

Open Access This article is distributed under the terms of the Creative Commons Attribution 4.0 International License (http://crea tivecommons.org/licenses/by/4.0/), which permits unrestricted use, distribution, and reproduction in any medium, provided you give appropriate credit to the original author(s) and the source, provide a link to the Creative Commons license, and indicate if changes were made.

\section{References}

1. Sugarbaker PH (1995) Patient selection and treatment of peritoneal carcinomatosis from colorectal and appendiceal cancer. World J Surg 19:235-240. doi:10.1007/BF00308632

2. Sugarbaker PH, Jablonski KA (1995) Prognostic features of 51 colorectal and 130 appendiceal cancer patients with peritoneal carcinomatosis treated by cytoreductive surgery and intraperitoneal chemotherapy. Ann Surg 221:124-132. doi:10.1097/ 00000658-199502000-00003 
3. Cao Y, Tan A, Gao F, Liu L, Liao C, Mo Z (2009) A metaanalysis of randomized controlled trials comparing chemotherapy plus bevacizumab with chemotherapy alone in metastatic colorectal cancer. Int J Colorectal Dis 24:677-685. doi:10.1007/ s00384-009-0655-9

4. Elias D, Gilly F, Boutitie F, Quenet F, Bereder JM, Mansvelt B, Lorimier G, Dubè P, Glehen O (2010) Peritoneal colorectal carcinomatosis treated with surgery and perioperative intraperitoneal chemotherapy: retrospective analysis of 523 patients from a multicentric French study. J Clin Oncol 28:63-68. doi:10.1200/ JCO.2009.23.9285

5. Kuijpers AM, Mirck B, Aalbers AG, Nienhuijs SW, de Hingh IH, Wiezer MJ, van Ramshorst B, van Ginkel RJ, Havenga K, Bremers AJ, de Wilt JH, Te Velde EA, Verwaal VJ, Kuijpers AM, Mirck B, Aalbers AG et al (2013) Cytoreduction and HIPEC in the Netherlands: nationwide long-term outcome following the Dutch protocol. Ann Surg Oncol 20:4224-4230. doi:10.1245/ s10434-013-3145-9

6. Verwaal VJ, van Ruth S, de Bree E, van Sloothen GW, van Tinteren H, Boot H, Zoetmulder FA (2003) Randomized trial of cytoreduction and hyperthermic intraperitoneal chemotherapy versus systemic chemotherapy and palliative surgery in patients with peritoneal carcinomatosis of colorectal cancer. J Clin Oncol 21:3737-3743. doi:10.1200/JCO.2003.04.187

7. Verwaal VJ, Kusamura S, Baratti D, Deraco M (2008) The eligibility for local-regional treatment of peritoneal surface malignancy. J Surg Oncol 98:220-223. doi:10.1002/jso.21060

8. de Cuba EM, Kwakman R, Knol DL, Bonjer HJ, Meijer GA, Te Velde EA (2013) Cytoreductive surgery and HIPEC for peritoneal metastases combined with curative treatment of colorectal liver metastases: systematic review of all literature and metaanalysis of observational studies. Cancer Treat Rev 39:321-327. doi:10.1016/j.ctrv.2012.11.003

9. Maggiori L, Bretagnol F, Ferron M, Chevalier Y, Panis Y (2011) Laparoscopic colorectal anastomosis using the novel $\operatorname{Chex}((\mathrm{R}))$ circular stapler: a case-control study. Colorectal Dis 13:711-715. doi:10.1111/j.1463-1318.2010.02246.x

10. Verwaal VJ, Zoetmulder FA (2004) Follow-up of patients treated by cytoreduction and chemotherapy for peritoneal carcinomatosis of colorectal origin. Eur J Surg Oncol 30:280-285. doi:10.1016/j. ejso.2003.12.003

11. de Cuba EM, Kwakman R, van Egmond M, Bosch LJ, Bonjer HJ, Meijer GA, te Velde EA (2012) Understanding molecular mechanisms in peritoneal dissemination of colorectal cancer : future possibilities for personalised treatment by use of biomarkers. Virchows Arch 461:231-243. doi:10.1007/s00428-012-1287-y

12. Taflampas P, Dayal S, Chandrakumaran K, Mohamed F, Cecil TD, Moran BJ (2014) Pre-operative tumour marker status predicts recurrence and survival after complete cytoreduction and hyperthermic intraperitoneal chemotherapy for appendiceal Pseudomyxoma Peritonei: analysis of 519 patients. Eur J Surg Oncol 40:515-520. doi:10.1016/j.ejso.2013.12.021

13. Pietras K, Ostman A (2010) Hallmarks of cancer: interactions with the tumor stroma. Exp Cell Res 316:1324-1331. doi:10. 1016/j.ejso.2013.12.021

14. Hanahan D, Weinberg RA (2011) Hallmarks of cancer: the next generation. Cell 144:646-674. doi:10.1016/j.cell.2011.02.013

15. Gupta GP, Massague J (2006) Cancer metastasis: building a framework. Cell 127:679-695. doi:10.1016/j.cell.2006.11.001

16. Fidler IJ (2003) The pathogenesis of cancer metastasis: the 'seed and soil' hypothesis revisited. Nat Rev Cancer 3:453-458. doi:10. 1038/nrc1098

17. Folkman J, Shing Y (1992) Angiogenesis. J Biol Chem 267:10931-10934

18. Gao D, Nolan DJ, Mellick AS, Bambino K, McDonnell K, Mittal V (2008) Endothelial progenitor cells control the angiogenic switch in mouse lung metastasis. Science 319:195-198. doi:10. 1126/science. 1150224

19. de Cuba EMV, de Hingh IHJT, Sluiter NR, Kwakman R, Coupé VMH, Beliën JAM, Verwaal VJ, Meijerink WJHJ, Delis-van Diemen PM, Bonjer HJ, Meijer GA, te Velde EA (2016) Angiogenesisrelated markers and prognosis after Cytoreductive surgery and Hyperthermic Intraperitoneal Chemotherapy for metastatic colorectal cancer. Ann Surg Oncol. doi:10.1245/s10434-015-5023-0

20. Logan-Collins JM, Lowy AM, Robinson-Smith TM, Kumar S, Sussman JJ, James LE, Ahmad SA (2008) VEGF expression predicts survival in patients with peritoneal surface metastases from mucinous adenocarcinoma of the appendix and colon. Ann Surg Oncol 15:738-744. doi:10.1245/s10434-007-9699-7

21. Du WW, Yang W, Yee AJ (2013) Roles of versican in cancer biology-tumorigenesis, progression and metastasis. Histol Histopathol 28:701-713

22. Ang LC, Zhang Y, Cao L, Yang BL, Young B, Kiani C, Lee V, Allan K, Yang BB (1999) Versican enhances locomotion of astrocytoma cells and reduces cell adhesion through its G1 domain. J Neuropathol Exp Neurol 58:597-605. doi:10.1079/ 00005072-199906000-0004

23. Labropoulou VT, Theocharis AD, Ravazoula P, Perimenis $\mathrm{P}$, Hjerpe A, Karamanos NK, Kalofonos HP (2006) Versican but not decorin accumulation is related to metastatic potential and neovascularization in testicular germ cell tumours. Histopathology 49:582-593. doi:10.1111/j.1365-2559.2006.02558.x

24. Ghosh S, Albitar L, LeBaron R, Welch WR, Samimi G, Birrer MJ, Berkowitz RS, Mok SC (2010) Up-regulation of stromal versican expression in advanced stage serous ovarian cancer. Gynecol Oncol 119:114-120. doi:10.1016/j.ygyno.2010.05.029

25. Ricciardelli C, Brooks JH, Suwiwat S, Sakko AJ, Mayne K, Raymond WA, Seshadri R, LeBaron RG, Horsfall DJ (2002) Regulation of stromal versican expression by breast cancer cells and importance to relapse-free survival in patients with nodenegative primary breast cancer. Clin Cancer Res 8:1054-1060

26. Suwiwat S, Ricciardelli C, Tammi R, Tammi M, Auvinen P, Kosma VM, LeBaron RG, Raymond WA, Tilley WD, Horsfall DJ (2004) Expression of extracellular matrix components versican, chondroitin sulfate, tenascin, and hyaluronan, and their association with disease outcome in node-negative breast cancer. Clin Cancer Res 10:2491-2498. doi:10.1158/1078-0432.CCR-030146

27. Du WW, Yang BB, Shatseva TA, Yang BL, Deng Z, Shan SW, Lee DY, Seth A, Yee AJ (2010) Versican G3 promotes mouse mammary tumor cell growth, migration, and metastasis by influencing EGF receptor signaling. PLoS One 5:e13828. doi:10. 1371/journal.pone.0013828

28. Ricciardelli C, Russell DL, Ween MP, Mayne K, Suwiwat S, Byers S, Marshall VR, Tilley WD, Horsfall DJ (2007) Formation of hyaluronan- and versican-rich pericellular matrix by prostate cancer cells promotes cell motility. J Biol Chem 282:10814-10825. doi:10.1074/jbc.M606991200

29. Kusumoto T, Kodama J, Seki N, Nakamura K, Hongo A, Hiramatsu Y (2010) Clinical significance of syndecan-1 and versican expression in human epithelial ovarian cancer. Oncol Rep 23:917-925. doi:10.3892/or_00000715

30. Casey RC, Oegema TRJ, Skubitz KM, Pambuccian SE, Grindle SM, Skubitz APN (2003) Cell membrane glycosylation mediates the adhesion, migration, and invasion of ovarian carcinoma cells. Clin Exp Metastasis 20:143-152. doi:10.1023/A:1022670501667

31. Lancaster JM, Dressman HK, Clarke JP, Sayer RA, Martino MA, Cragun JM, Henriott AH, Gray J, Sutphen R, Elahi A, Whitaker RS, West M, Marks JR, Nevins JR, Berchuck A (2006) Identification of genes associated with ovarian cancer metastasis using microarray expression analysis. Int $\mathrm{J}$ Gynecol Cancer 16:1733-1745. doi:10.1111/j.1525-1438.2006.00660.x 
32. Fu Y, Nagy JA, Brown LF, Shih SC, Johnson PY, Chan CK, Dvorak HF, Wight TN (2011) Proteolytic cleavage of versican and involvement of ADAMTS-1 in VEGF-A/VPF-induced pathological angiogenesis. J Histochem Cytochem 59:463-473. doi: $10.1369 / 0022155411401748$

33. Zheng PS, Wen J, Ang LC, Sheng W, Viloria-Petit A, Wang Y, Wu Y, Kerbel RS, Yang BB (2004) Versican/PG-M G3 domain promotes tumor growth and angiogenesis. FASEB J 18:754-756. doi:10.1096/fj.03-0545fje

34. Verwaal VJ, van Ruth S, Witkamp A, Boot H, van Slooten G, Zoetmulder FA (2005) Long-term survival of peritoneal carcinomatosis of colorectal origin. Ann Surg Oncol 12:65-71. doi:10. 1007/s10434-004-1167-z

35. Kerkhof MH, Ruiz-Zapata AM, Bril H, Bleeker MC, Belien JA, Stoop R, Helder MN (2014) Changes in tissue composition of the vaginal wall of prementopausal women with prolapse. Am J Obstet Gynecol 210:168.e1-9. doi:10.1016/j.ajog.2013.10.881

36. Breslow N (1970) A generalized Kruskal-Wallis test for comparing $\mathrm{K}$ samples subject to unequal patterns of censorship. Biometrika 57:579-594. doi:10.1093/biomet/57.3.579

37. de Wit M, Belt EJ, Delis-van Diemen PM, Carvalho B, Coupé VM, Stockmann HB, Bril H, Beliën JA, Fijneman RJ, Meijer GA (2013) Lumican and versican are associated with good outcome in stage II and III colon cancer. Ann Surg Oncol 20(Suppl 3):S348-S359. doi:10.1245/s10434-012-2441-0

38. Read JT, Rahmani M, Boroomand S, Allahverdian S, McManus BM, Rennie PS (2007) Androgen receptor regulation of the versican gene through an androgen response element in the proximal promoter. J Biol Chem 282:31954-31963. doi:10.1074/ jbc.M702099200

39. Portilla AG, Shigeki K, Dario B, Marcello D (2008) The intraoperative staging systems in the management of peritoneal surface malignancy. J Surg Oncol 98(4):228-231. doi:10.1002/jso. 21068

40. Williams E, Martin S, Moss R, Durrant L, Deen S (2012) Coexpression of VEGF and CA9 in ovarian high-grade serous carcinoma and relationship to survival. Virchows Arch 461(1):33-39

41. Shaheen RM, Ahmad SA, Liu W, Reinmuth N, Jung YD, Tseng WW et al (2001) Inhibited growth of colon cancer carcinomatosis by antibodies to vascular endothelial and epidermal growth factor receptors. Br J Cancer 85(4):584-589. doi:10.1054/bjoc.2001. 1936

42. Imaizumi T, Aoyagi K, Miyagi M, Shirouzu K (2010) Suppressive effect of bevacizumab on peritoneal dissemination from gastric cancer in a peritoneal metastasis model. Surg Today 40(9):851-857

43. Bai Y, Deng H, Yang Y, Zhao X, Wei Y, Xie G et al (2009) VEGF-targeted short hairpin RNA inhibits intraperitoneal ovarian cancer growth in nude mice. Oncology 77(6):385-394. doi:10.1159/000279385

44. Diniz Bizzo SM, Meira DD, Lima JM, Mororó JDS, Casali-daRocha JC, Ornellas MHF (2010) Peritoneal VEGF burden as a predictor of cytoreductive surgery outcome in women with epithelial ovarian cancer. Int J Gynaecol Obstet 109(2):113-117. doi:10.1016/j.ijgo.2009.11.021

45. Varghese S, Burness $\mathrm{M}, \mathrm{Xu} \mathrm{H}$, Beresnev T, Pingpank J, Alexander HR (2007) Site-specific gene expression profiles and novel molecular prognostic factors in patients with lower gastrointestinal adenocarcinoma diffusely metastatic to liver or peritoneum. Ann Surg Oncol 14(12):3460-3471. doi:10.1245/ s10434-007-9557-7

46. Zebrowski BK, Liu W, Ramirez K, Akagi Y, Mills GB, Ellis LM (1999) Markedly elevated levels of vascular endothelial growth factor in malignant ascites. Ann Surg Oncol 6(4):373-378. doi:10.1007/s10434-999-0373-0
47. Yoshikawa T, Tsuburaya A, Miyagi Y, Sekiguchi H, Kimura M, Cho H, Kobayashi O (2006) Up-regulation of hypoxia-inducible factor-1 alpha and VEGF mRNAs in peritoneal dissemination of patients with gastric cancer. Anticancer Res 26(5B):3849-3853

48. Gerber SA, Rybalko VY, Bigelow CE, Lugade AA, Foster TH, Frelinger JG, Lord EM (2006) Preferential attachment of peritoneal tumor metastases to omental immune aggregates and possible role of a unique vascular microenvironment in metastatic survival and growth. Am J Pathol 169(5):1739-1752. doi:10. 2353/ajpath.2006.051222

49. Kobold S, Hegewisch-Becker S, Oechsle K, Jordan K, Bokemeyer C, Atanackovic D (2009) Intraperitoneal VEGF inhibition using bevacizumab: a potential approach for the symptomatic treatment of malignant ascites? Oncologist 14(12):1242-1251. doi:10.1634/theoncologist.2009-0109

50. Ninomiya S, Inomata M, Tajima M, Ali AT, Ueda Y, Shiraishi N, Kitano S (2009) Effect of bevacizumab, a humanized monoclonal antibody to vascular endothelial growth factor, on peritoneal metastasis of MNK-45P human gastric cancer in mice. J Surg Res 154(2):196-202. doi:10.1016/j.jss.2008.08.017

51. Shaheen RM, Tseng WW, Vellagas R, Liu W, Ahmad SA, Jung YD, Reinmuth N, Drazan KE, Bucana CD, Hicklin DJ, Ellis LM (2001) Effects of an antibody to vascular endothelial growth factor receptor-2 on survival, tumor vascularity, and apoptosis in a murine model of colon carcinomatosis. Int J Oncol 18:221-226

52. Klaver YLB, Leenders BJM, Creemers G-J, Rutten HJT, Verwaal VJ, Lemmens VEPP et al (2013) Addition of biological therapies to palliative chemotherapy prolongs survival in patients with peritoneal carcinomatosis of colorectal origin. Am J Clin Oncol 36(2):157-161. doi:10.3892/ijo.18.2.221

53. Ceelen W, Van NY, Putte DV, Pattyn P (2014) Neoadjuvant chemotherapy with bevacizumab may improve outcome after cytoreduction and hyperthermic intraperitoneal chemoperfusion (HIPEC) for colorectal carcinomatosis. Ann Surg Oncol 21:3023-3028. doi:10.1245/s10434-014-3713-7

54. Eveno C, Passot G, Goéré D, Soyer P, Gayat E, Glehen O, Elias D, Pocard M (2014) Bevacizumab doubles the early postoperative complication rate after cytoreductive surgery with hyperthermic intraperitoneal chemotherapy (HIPEC) for peritoneal carcinomatosis of colorectal origin. Ann Surg Oncol 21:1792-1800. doi:10.1245/s10434-013-3442-3

55. Theocharis AD, Skandalis SS, Tzanakakis GN, Karamanos NK (2010) Proteoglycans in health and disease: novel roles for proteoglycans in malignancy and their pharmacological targeting. FEBS J 277:3904-3923. doi:10.1111/j.1742-4658.2010.07800.x

56. Sheng W, Dong H, Lee DY, Lu WY, Yang BB (2007) Versican modulates gap junction intercellular communication. J Cell Physiol 211:213-219. doi:10.1002/jcp.20921

57. Cattaruzza S, Schiappacassi M, Kimata K, Colombatti A, Perris R (2004) The globular domains of PG-M/versican modulate the proliferation-apoptosis equilibrium and invasive capabilities of tumor cells. FASEB J 18:779-781. doi:10.1096/fj.03-0660fje

58. Du WW, Fang L, Yang W, Sheng W, Zhang Y, Seth A, Yang BB, Yee AJ (2012) The role of versican G3 domain in regulating breast cancer cell motility including effects on osteoblast cell growth and differentiation in vitro-evaluation towards understanding breast cancer cell bone metastasis. BMC Cancer 12:341. doi:10.1186/1471-2407-12-341

59. Wu Y, Wu J, Lee DY, Yee A, Cao L, Zhang Y, Kiani C, Yang BB (2005) Versican protects cells from oxidative stress-induced apoptosis. Matrix Biol 24:3-13. doi:10.1016/j.matbio.2004.11.007

60. Wu Y, Chen L, Zheng PS, Yang BB (2002) beta 1-Integrin-mediated glioma cell adhesion and free radical-induced apoptosis are regulated by binding to a $\mathrm{C}$-terminal domain of PG-M/versican. J Biol Chem 277:12294-12301. doi:10.1074/jbc.M110748200 
61. LaPierre DP, Lee DY, Li SZ, Xie YZ, Zhong L, Sheng W, Deng Z, Yang BB (2007) The ability of versican to simultaneously cause apoptotic resistance and sensitivity. Cancer Res 67:4742-4750. doi:10.1158/0008-5472.CAN-06-3610

62. Straussman R, Morikawa T, Shee K, Barzily-Rokni M, Qian ZR, Du J, Davis A, Mongare MM, Gould J, Frederick DT, Cooper ZA, Chapman PB, Solit DB, Ribas A, Lo RS, Flaherty KT, Ogino S, Wargo JA, Golub TR (2012) Tumour micro-environment elicits innate resistance to RAF inhibitors through HGF secretion. Nature 487:500-504. doi:10.1038/nature11183

63. Ween MP, Hummitzsch K, Rodgers RJ, Oehler MK, Ricciardelli C (2011) Versican induces a pro-metastatic ovarian cancer cell behavior which can be inhibited by small hyaluronan oligosaccharides. Clin Exp Metastasis 28:113-125. doi:10.1007/s10585010-9363-7

64. Yee AJ, Akens M, Yang BL, Finkelstein J, Zheng PS, Deng Z, Yang B (2007) The effect of versican G3 domain on local breast cancer invasiveness and bony metastasis. Breast Cancer Res 9:R47. doi:10.1186/bcr1751

65. Brown LF, Guidi AJ, Schnitt SJ, Van De Water L, Iruela-Arispe ML, Yeo TK, Tognazzi K, Dvorak HF (1999) Vascular stroma formation in carcinoma in situ, invasive carcinoma, and metastatic carcinoma of the breast. Clin Cancer Res 5:1041-1056

66. Hlatky L, Hahnfeldt P, Folkman J (2002) Clinical application of antiangiogenic therapy: microvessel density, what it does and doesn't tell us. J Natl Cancer Inst 94(12):883-893. doi:10.1093/ jnci/94.12.883

67. Chen L, Endler A, Shibasaki F (2009) Hypoxia and angiogenesis: regulation of hypoxia-inducible factors via novel binding factors. Exp Mol Med 41(12):849-857. doi:10.3858/emm.2009.41.12.103

68. Voutilainen K, Anttila M, Sillanpää S, Tammi R, Tammi M, Saarikoski S, Kosma VM (2003) Versican in epithelial ovarian cancer: relation to hyaluronan, clinicopathologic factors and prognosis. Int J Cancer 107:359-364. doi:10.1002/ijc.11423

69. Kwakman R, de Cuba EM, de Winter JP, de Hingh IH, Delis-van Diemen PM, Tijssen M, Rooimans MA, Krijgsman O, Carvalho B, Peters GJ, Bonjer HJ, Meijer GA, Te Velde EA (2015) Tailoring heated intraperitoneal mitomycin $\mathrm{C}$ for peritoneal metastases originating from colorectal carcinoma: a translational approach to improve survival. $\mathrm{Br} \mathrm{J}$ Cancer 112(5):851-856. doi:10.1038/bjc.2015.18 